\title{
Integrated Programs and Cultural Literacies: Using Writing to Help Engineering Students Transition to the Cultural Literacies of College
}

\author{
Sarah Duerden, Jeanne Garland, Christine Helfers, \& Ronald Roedel \\ Department of English/Department of Electrical Engineering \\ Arizona State University, Tempe, AZ 85287
}

\begin{abstract}
As educators who work with first-year students, we are all well aware of how difficult some students find the transition to college, particularly first-year engineering students. Of course, some students fail because they are ill prepared for the courses they are taking. Others are too easily distracted by their newfound freedoms. Nevertheless, there is a body of students whose ACT/SAT scores and high school grades suggest that they should easily adapt to the college environment, and yet some of these students do poorly. Our experience in teaching the integrated program suggests that these students experience difficulty in their freshman year because they feel threatened by the new learning environments, teaching methods, and demands that they are experiencing, and they often have problems adapting to these. In developing our ideas for integrated modules for the first-year program, we discovered that this notion of transition was important in all the classes. In English, for example, students need to abandon those techniques such as the "five-paragraph theme," which may have worked for them in the past. Similarly, in engineering, students need to abandon their linear problem-solving techniques that have worked in the past and allow themselves to spend more time on generating multiple solutions. Both changes are part of what we might call the "cultural literacies" of the subject -that is, the "different sets of reading, writing, thinking, listening, and behavioral skills that make up the numerous communities of the academic world and beyond." ${ }^{1}$ Therefore, one of our writing assignments helps students transition to the cultural literacies involved in college. In this assignment, we ask students to examine the various changes they are experiencing and to determine the reasons they need to make these changes for success in their first-year courses. The assignment then asks students to internalize and apply those changes. In this paper, we will discuss the kinds of transitions students need to make, and we will explain how the assignment we have developed helps students to internalize those transitions.
\end{abstract}

\section{Introduction: The Integrated Program}

The Freshman Integrated Program in Engineering (FIPE) at Arizona State University, which was developed through funding partnerships with the National Science Foundation 
sponsored Foundation Coalition, is a course for first-year engineering students that integrates engineering, calculus, physics, and English Composition. Our integration has involved using the first-year-engineering course (delivered both semesters) as an umbrella so that each of the other courses integrates with engineering. While many students have been successful in the prog ram, we have seen that some students perform less well than standard indicators suggest they should. We realized that for these students, their failure stemmed not from an inability to do the work, but rather from their inability to adapt to the varying literacies required in the disparate courses they encounter in their freshman year. In this paper, we will address the transitions first-year students must make when they enter engineering and show how assignments in Freshman English can be developed to help students understand what those transitions are and how they must adapt to succeed in the university communities they encounter.

\section{Background to the Problem}

Retention of freshmen has become a focus in our nation today because of the high rate of attrition at many college universities. One university that has a particular concern about retention is Arizona State University, a public institution that is mandated to provide an education for as many students as possible, resulting in an acceptance rate of $80 \% .^{2}$ The lower freshmen retention rate of $74 \%$ and even less impressive graduation rate of under $50 \%$ in 6 years at ASU suggests that this high rate of acceptance also poses real challenges for ASU educators to

help with student persistence. ${ }^{2}$ One way that ASU has met these challenges is to build programs for freshmen that provide intervention to increase the retention rate, such as the Academic Success at the University (UNI 100), Summer Bridge programs, and other learning community programs, such as the Freshman Retention Effort in Engineering Housing. 
Because engineering is one of those fields in which less than half of the students who begin their studies in engineering actually graduate in the field, ASU has also encouraged fostering programs, such as the Freshmen Integrated Program in Engineering (FIPE). In addition to delivering course content in which concepts are integrated among the various classes, instructors in this program also recognize the importance of helping students adapt in the first few weeks, which research indicates is the most important determinant of whether a student will persist and succeed or leave the university. ${ }^{2}$ These adaptations include social, emotional, and academic transitions. Thus, researchers have noted a perceived lack of social support correlates to higher student attrition rates. ${ }^{3}$ In fact, even though academic ability may predict retention, emotional and social adjustment also predicts attrition. ${ }^{4}$ Furthermore, while some students take the transition to college life in stride, others are overwhelmed and may drop out. ${ }^{5}$ Such students may require counseling and other services to handle the emotional transition, which may result in improved retention rates. ${ }^{6}$ Another important area of retention research focuses on academic transitions, and includes student adaptation to the theoretical and abstract subject matter common in university classes. In response to the findings of this research, universities have created various academic support services including tutoring centers and mentoring programs designed to help students adjust to the higher expectations of the university.

In addition to the problems outlined above, students often feel threatened by unfamiliar learning environments in which there are different teaching methods and classroom management. Further their own learning styles are incompatible with teaching methods of their instructors. To understand the challenges students face in their transitions into the cultural literacies of college, 
we considered Felder and Silverman's index of learning styles (ILS). They identify preferences

for learning as Active-Reflective, Sensing-Intuitive, Visual-Verbal, and Sequential-Global. ${ }^{7}$

Felder identifies active learners as those who like to experiment with working things out working with others, while reflective learners are those who prefer thinking things out and working by themselves. Sensing learners prefer collecting facts and following procedures, while intuitive learners are more oriented toward concepts, theories, and significance of meaning. Felder describes visual learners as those who prefer visual representations and verbal learners those who prefer written and spoken explanations. And finally, Felder considers sequential learners as those who are more orderly and linear in their thinking, who like to learn in small steps, compared to global learners, who are more holistic in their thinking and prefer to learn in large leaps. $^{7}$

\section{Description of the Problem}

We agree with Felder ${ }^{8}$ that adjusting teaching approaches and methods to improve student retention helps, but these changes do not address the core academic problem: incoming students do not understand how to negotiate the various academic communities they will encounter. In each of these communities are different sets of reading, writing, thinking, listening, and behavioral skills, often defined as cultural literacies, and the student needs not only to recognize that these different communities exist but also to learn how to work within these communities. However, what many students do is try to make each different academic community fit with the individual approach to reading, writing, and learning that has consistently worked for them in the past. For example, most educators recognize that writing a research report in one of the social sciences, such as Communications, requires a different approach than 
would be needed if one were writing an analysis of a particular poet for a class in English literature. The types of research, what constitutes evidence, the databases consulted, the vocabulary, the genre of the paper, and even the style manual would all differ. But we often forget that our students have not encountered these differences, and when they try to write a report for one subject using the approach they have always used successfully in another subject, they are almost certainly bound to fail. Nor are these differences limited to writing. When, for example, students try to solve the more complex math and physics problems they encounter in their first year of college by using the "plug and chug" method they employed in high school, they also fail.

\section{Earlier Solutions}

In our integrated program for first-year engineering students that combines engineering, calculus, physics, and English, the instructors endeavor to create syllabi in which course content overlaps. We try to ensure that concepts in the various classes are taught in a sequence that allows for reinforcement in the various subjects. As English teachers, when we first began our integrated program, we endeavored to lessen the differences between the academic communities within the integrated program, and this proved to be helpful for the students. For example, we discovered some powerful connections between engineering and English. ${ }^{9}$ We saw strong parallels between writing process and the engineering design process. Both involve recursive activities and invention activities. Further, both engineers and writers use heuristics, sets of systematic questions designed to generate ideas: for engineers heuristics are employed in the brainstorming stage of design, and for writers heuristics are employed in the invention stage of writing. Therefore, we developed a unit in the English class focusing on the parallels between 
the design process and the writing process, and for one assignment, we asked students to develop an article for students who are new to engineering outlining how their familiarity with the writing process could help them understand and work through the processes of the design process. This integration with engineering on a conceptual level helped students embrace and work with unfamiliar concepts, and from their papers, we could also see that some students were able to connect the design process and the writing process to the problem-solving processes they were employing in calculus and physics.

Nevertheless, we also found different subjects do involve specialized language and specialized ways of thinking and consequently, specialized ways of writing as rhetoricians like Patricia Bizzell have pointed out. ${ }^{10}$ Because this is a particularly sophisticated concept, we felt that by highlighting the differences, we could make what was often invisible and so problematic for students more visible and less problematic, and we could do this in the first-year writing classes. In traditional first-year writing classes, students complete a number of assignments that help them develop their writing, and the subject matter of the class is left up to the individual teacher. We decided that our subject matter for our writing assignments should be the cultural literacies of the various academic communities a student must negotiate in the study of engineering and the changes our students would have to make. Making learning the subject matter gives the freshmen writing course a metacognitive focus, forcing students into a systematic inquiry about their own learning. This assignment has confirmed our belief that writing classes are ideal sites for such reflective activity. As Joel A. English explains, metacognitive activities provide "writing students with the ability to describe how and what they have learned." 11 


\section{Method}

We developed a curriculum in our first-year writing class in which the subject matter of the papers that the students write is these cultural literacies that they are encountering as firstyear engineers. In the first semester we have a sequence of four related papers that ask students to write about the various cultural literacies they will need to master as engineering students in the FIPE program that integrates engineering, calculus, physics, and English. We begin by asking students to explore the various literacies they are encountering as first-year engineering students and advise high school students considering engineering about the changes they will need to make in order to succeed in engineering. Our second paper builds on this notion of differing communities and differing literacies by exploring the world of professional engineering. Students write about the cultural literacies engineers face in the professional world. Our third then focuses on one particular literacy for engineers (both students and professionals), that of ethics. Our last paper, a team paper, asks students to explain how their design for an engineering project demonstrates that they have employed ethics. This sequenced approach allows the students to grasp the notion of multiple literacies and the changes they need to make to succeed as a student and as a professional.

\section{Background to the Assignment}

The first assignment is particularly helpful to students because it allows students to explore in writing the various demands made of them by their different professors. To prepare for the assignment, we give students a number of readings that we discuss in class. We begin with some readings from Keith Hjortshoj's book The Transition to College Writing ${ }^{12}$ in which 
he discusses the various differences between writing in high school and writing in college. We also assign a number of readings from Samuel Florman's The Introspective Engineer ${ }^{13}$ in which he defines engineering and the various skills successful engineers must develop. Then we examine two more difficult and focused readings that really ask the students to reflect on teaching and learning styles. The first, Paolo Frieire's "Banking Concept of Education" proves to be a powerful and insightful reading for students. In this selection from his work Pedagogy of the Oppressed, Freire uses the metaphors of banking to reveal how traditional teaching methods do little to engage and promote real learning. He shows that too often students are viewed as piggy banks in which teachers deposit knowledge: "Instead of communicating, the teacher issues communiqués and makes deposits which the students patiently receive, memorize, and repeat."14 A second article, "On the Uses of a Liberal Education: 1. As Lite Entertainment for Bored College Students" by Mark Edmundson, asks students to take a more introspective look at themselves and the way they are behaving in college. In this particular article, Edmundson explores how the culture of his students and the culture of the university conspire to repress his students so that they are "desperate to blend in, to look right, not to make a spectacle of themselves" ${ }^{15}$ so that students are disengaged in the classroom. Before students begin the assignment, they have written a number of reflective journals that ask them to explore how the concepts discussed in the readings apply to themselves. For example, we ask students to consider when and where they have been exposed to the banking concept of education, and in what subjects might this approach be taken. In addition, we ask them to reflect on the image they think they are currently projecting in the classroom when they read Edmundson's article. Similarly, we ask them to think about what specific writing practices and work habits they need 
to change and why as they read the selections from Hjortshoj's book. Each of these reflective journals generates material that they may use in the assignment.

\section{The Assignment}

Once we have helped students develop a background in this subject matter, we then give them the assignment, which asks students to solve a problem:

\section{Problem:}

From your reading and from your experience to date, you can see that the transition from high school to college is quite challenging and involves a number of adjustments. Some students make these adjustments easily; however, for others, the transition is much more difficult. In addition to new lifestyles and friends, many students find it hard to adjust to the new teaching and learning styles employed in the college classrooms. This is particularly true in engineering where courses are challenging and employ different teaching and learning styles from those typically employed in high school. As a result, a number of students either drop out of engineering or drop out of college.

\section{Solution:}

Therefore because you are a freshman in engineering, the Associate Dean of Academic Affairs has asked you to prepare a paper that would be distributed to high school students interested in engineering in which you explain the cultural literacies involved in the study of engineering here at Arizona State University. You will look at what is involved in the study of engineering, the skills a student needs to develop, the way various classes are taught, and the expectations of the various professors. You might want to contrast some of this with typical high school experiences. 


\section{Results and Assessment}

This assignment asks students to reflect upon the things they are struggling with and consider the demands of each course, the expectations of each professor, the language and concepts they are being asked to master, the teaching styles employed, and how all this differs from their high school experiences. Assessment in English was done through grading the paper that the students wrote and reviewing the reflections they wrote on writing the paper. We matched the goals for the paper, outlined on the assignment sheet, with a grading rubric that would allow us to focus on how well the students understood the concept of cultural literacies in the various classes in the FIPE program. Over $90 \%$ of the students earned a passing grade on the assignment, which indicates that they had clearly met the goals of understanding the concept of cultural literacies, and over $55 \%$ had exceeded those goals by earning an "A" or "B" grade. We found that the students really did explore these concepts in their papers, and from our discussions with the integrated faculty team, we found that many students began to understand the difficulties they were experiencing with various subjects. For example, as a result of the assignment, several students noted in their reflective responses that they were now able to identify when teachers were employing active and cooperative teaching strategies and how they as students needed to respond. They began to see that such approaches were not taken because teachers were lazy and expected students to "teach themselves." Instead they saw that they were being asked to be involved in their own learning, and when they reflected on Paulo Freire's banking concept and Mark Edmundson's article, they saw why their involvement in the learning process was so crucial to moving out of their "high school mode" as one student so aptly described his earlier responses in the class. 
Similarly, students understood that the same concept could be couched in different terms in different classes and the different terminology was not due to the professors' inability to agree on one term, but rather was due to the specialized language involved in each subject. As English teachers, we were especially pleased with the ways the assignment forced the students to think about writing and their individual writing processes. The readings from Keith Hjortshoj's work on the "footstool essay" (5-paragraph theme), "writing processes" and college teachers' expectations helped them understand and apply our suggestions for writing. For example, several students discussed in their assignment the limitations of the "footstool essay," why they it had served them in the past, and why it could no longer serve them adequately in college writing. They noted how this limited approach to writing a paper forced them into a linear process so that once they had generated "the requisite three supporting points" all good papers need, they would stop trying to discover other ideas. Again we feel that this is quite a sophisticated realization that students need to discover if they are to adjust successfully to the various cultural literacies they will encounter in college.

\section{Further Assessment}

To see whether students had retained an understanding of this notion of cultural literacies, we conducted further assessment in the second semester of their FIPE program. In the English class, we gave them the following prompt:

"Last semester we worked with the notion of cultural literacies. In paper one, we explored the idea that each academic class that you take involves a specific vocabulary (way of talking about subjects), specific writing skills and types of papers, and specific ways of thinking about things. How did understanding the notion that there are various cultural literacies that you 
negotiate in the university help you in your first semester? Explain with concrete details. Then consider how this understanding is helping you this semester"

We gave the students about 15 minutes of class time to complete this journal, and then we asked them to email their journal response to us. Even though they had very little time to complete this work, we were impressed with their responses, which showed that they had understood the notion of cultural literacies and that understanding helped them make the transition to college more easily. Three primary threads emerged from the journal: first, students recognized that the transition to college involved adjusting to different literacies; second students understood that teaching styles and teachers' expectations differ dramatically from high school and from course to course within college; and finally, some students were enabled to make social and cultural adjustments in their personal lives by gaining an understanding of cultural literacies. In responding to the prompt, representative comments included the following: "One of the main surprises was the fact that professors from different subjects often used same terminologies but with different meaning . . in high school I never encountered that. For example in my physics and engineering courses the professors often use the word 'model' ... in physics we had to define which models we used for each problem we solved whereas in engineering we had to develop our own models and design them." Similarly, another student notes that "in high school, the word 'design' meant to create and build something tangible. In college, however, the word 'design' has taken on a few different meanings in each class. In English, to design something can mean to envision something in my mind like a thesis statement or a body diagram for a research paper. In math the word 'design' means to think of new ways to solve a problem, to find alternative methods to solve each problem in order to master each skill. In physics, the word 'design' means to illustrate an idea on paper and explain to the class. 
In engineering, the word 'design' comes closest to the meaning in high school in that it means to create something in your head and on paper first and then build and construct it." These comments are typical of the responses students made, and we feel that they clearly demonstrate that students have understood and internalized the concept of cultural literacies in college.

The second significant theme that emerged in their reflective comments involved the differences they discovered in teaching styles and teachers' expectations. Once again we impressed with the depth and comprehension exhibited in the students' responses. For example, one student noted "during the first month of my college career I believed that all the professors would teach their classes the same way, much as they did in high school. This proved to be a hindrance to my grades. The first few assignments in English were designed to teach us that college is different from high school and that each professor has their own way of teaching a class. Once I caught on to this, I was able to adjust my work and study habits." Another student noted that "the laid-back, indifferent tactics I used in high school did not prove to be sufficient any more." Students agreed with one peer who said that "every class in the FIPE program has different writing expectations." According to one student, "in English teachers expect you to write essays that argue specific themes; in our engineering class, we learned that this essay format won't work." Clearly these students have also internalized the notion that they must adapt their own learning styles to teachers' methods and expectations.

Unexpectedly, the third theme apparent in the students' responses was their application of cultural literacies to their personal lives. A number of students commented on how understanding cultural literacies enabled them to adjust socially and emotionally to their new environment. For example, one student noted that by working with the notion of cultural literacies, he "was able to use this knowledge outside the classroom to better [his] overall 
experience . . by seeing clearly what was available on campus, how those social things matched [his] own interests, and then how to communicate with the people of the group ... how to interact with them in their "language," which differed from group to group." For one student, this notion of cultural literacies made her realize that "to understand fully, it was necessary to be inquisitive and unafraid to use the resources fully." Because this student's particular culture is one that does not encourage students to question and discuss, this realization really helped. This student felt that "living away from home, making new acquaintances, and motivating myself to do the necessary things made everything appear, at first, tiresome and confusing. After being exposed to such things [the notion of cultural literacies], I feel more confident in my abilities."

\section{Conclusions}

We feel strongly that this kind of sequenced course in which the subject matter is the cultural literacies of the discipline the students are pursuing is beneficial to the students both in terms of helping them become better writers and in terms of them becoming better students. The kinds of metacognitive activities involved in the first two papers help students connect their own ways of learning to the academic world in which they find themselves. They see not only what changes they need to make to their study habits, but they understand why they need to make those changes. They recognize the teaching strategies employed, and they understand why those teaching strategies are employed. They are able to identify the professor's expectations and see different ways of meeting those expectations. And when students are able to articulate these concepts, they are better able to meet the challenges of the transition to college. 


\section{References}

${ }^{1}$ Belasco, S. Constructing Literacies. Fortworth, Allyn \& Bacon, 2001, p. 2

${ }^{2}$ Anderson-Rowland, M. \& J. Urban. "Evaluating Freshman Retention Efforts in Engineering Housing,” Proceedings, FIE Conference, October 2001, Reno, Nevada, Session TG4, p. 1.

${ }^{3}$ Gerdes, H. \& Mallinckroft, B. "Emotional, Social, and Academic Adjustment of College Students: A Longitudinal Study," Journal of Counseling \& Development, Volume 7, Number 2, Jan/Feb 94. pp. 281-289.

${ }^{5}$ Wintre, M.G \& Yaffe, M. "First-Year Students' Adjustment to University Life as a Function of Relationships with Parents," Journal of Adolescent Research, Volume 15, Number 1, pp. 9-38.

${ }^{6}$ Leong, F. \& Bonz, M. “Coping Styles as Predictors of College Adjustment Among Freshman,” Counseling Psychology Quarterly, Jun 97, Volume 10, Number 2, pp. 211-222.

${ }^{7}$ Van Zwanenberg, N., L. F. Wilkinson, \& A. Anderson. "Felder and Silverman's Index of Learning Styles and Honey and Mumford's Learning Styles, How Do They Compare and Do They Predict Academic Performance?" Educational Psychology, Volume 20, Number 3, Sep. 2000, pp. 365-380.

${ }^{8}$ Felder, R. M. “Matter of Style,” ASEE Prism, Volume 6, 1996, pp. 18-23.

${ }^{9}$ Duerden, S., J. Garland, C. Helfers, \& R. Roedel. "Integration of first year English and Introduction to Engineering Design: A Path to Explore the Literacy and Culture of Engineering." ASEE Conference, Session 2453, June 2001.

${ }^{10}$ Bizzell, P., Academic Discourse and Critical Consciousness, University of Pittsburgh, Pittsburgh, 1992 p. 222.

${ }^{11}$ English, J. “Basis of Metacognition," Kairos, http://english.ttu.edu/kairos/3.1/features/metacog.html Jan 1, 2002. 
${ }^{12}$ Hjortshoj, K. The Transition to College Writing, Bedford St. Martins, New York, 2001.

${ }^{13}$ Florman, S. The Introspective Engineer, St. Martins, New York, 1996.

${ }^{14}$ Freire, P. “The Banking Concept of Education,” Constructing Literacies, Ed. Susan Belasco,

Fortworth, Allyn \& Bacon, 2001, p. 339.

${ }^{15}$ Edmundson, M. "On the Uses of a Liberal Education: 1. As Lite Entertainment for Bored

College Students," Constructing Literacies, Ed. Susan Belasco, Fortworth, Allyn \& Bacon, 2001, p. 231.

SARAH DUERDEN

Sarah Duerden is a lecturer in Rhetoric and Composition in the English Department at Arizona State University. She received her PhD. in English in 1992 and her MA in English in 1986 from Arizona State University. She earned her BA in English at Sheffield University. She currently teaches in the Freshman Integrated Program for Engineering (FIPE) and also teaches Professional Writing, Academic Writing, and First-Year Composition.

\section{JEANNE GARLAND}

Jeanne Garland is an instructor in Rhetoric and Composition in the English Department at Arizona State University. She received her MA in Rhetoric from New Mexico State University, and she worked as a technical writer for the Engineering Research Center at New Mexico State University. She currently teaches in the Freshman Integrated Program for Engineering (FIPE) and also teaches Professional Writing, Technical Editing and First-Year Composition courses.

\section{CHRISTINE HELFERS}

Christine Helfers is an instructor in Rhetoric and Composition in the English Department at Arizona State University. She received her MA in Rhetoric from Arizona State University in 1992. She currently teaches in the Freshman Integrated Program for Engineering (FIPE) and also teaches Persuasive Writing, Reflective Writing and First-Year Composition courses.

\section{RONALD ROEDEL}

Ronald Roedel is a professor in the Department of Electrical Engineering and Associate Dean for Academic Affairs in the College of Engineering and Applied Sciences at Arizona State University. He received his PhD in Electrical Engineering in 1976 from UCLA and his BSE in Electrical Engineering in 1971 at Princeton University. He currently teaches in the Freshman Integrated Program for Engineering (FIPE) as well as graduate classes in Electrical Engineering. He also carries out research in the area of semiconductor materials and devices. He is the ASU Parents' Association Professor of the Year for 1999-2001. 